\title{
EON・
}

\section{ISMTE Board of Directors Quarterly Update}

\section{Erin Landis ${ }^{1}$}

${ }^{1}$ Vice President, Publications American Gastroenterological Association

Published on: Sep 15, 2021

License: Creative Commons Attribution-NoDerivatives 4.0 International License (CC-BYND 4.0). 


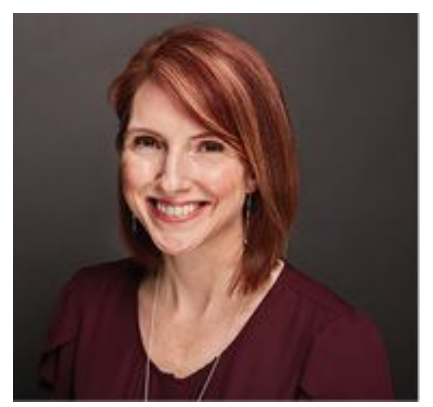

Erin Landis, ISMTE President (on behalf of the ISMTE Board of Directors)

Greetings from the ISMTE Board of Directors (BOD). We are now past the midway mark of 2021, a year that feels more optimistic than the last in some parts of the world, and yet more concerning in other regions as the Delta variant takes hold and vaccination targets are unmet. Globally, we are not yet out of the woods. Despite these geographical differences, we remain united in the fight to end the pandemic, finding commonalities among us where before we might not have seen them. Here too, at ISMTE, we strive to see how we are united regardless of our regional diversity, hence the theme of our upcoming global event "Unified Progress: Moving Forward Together in Scholarly Communications." Below we provide you with a brief preview of the event, as well as an update on what the ISMTE BOD and committees have been working on during the last few months.

\section{Global Event 2021}

From October 11th through October 14th, ISMTE will host its first-ever global event. The event will feature programming from ISMTE' s three primary regions-Asia Pacific, Europe, and North America-at times convenient for members in each of those time zones. Also, the programming for each of the three primary days (October 12-14) will focus on distinct themes: DEI, Journal Management, and Open Access. Not only will you have the chance to attend programming in your region, you can also attend the other regions' sessions live or watch them on demand. This is an excellent opportunity for you to learn how similar issues in our industry affect and are addressed by different parts of the world and to network with your colleagues from across the globe.

\section{Virtual Event Content Now Available}

Speaking of on-demand content, you now can watch all of the content from last year' $s$ three virtual events. If you were an attendee at one (or more) of the events, the content is freely accessible to you (to access the content freely, please see the promo code you

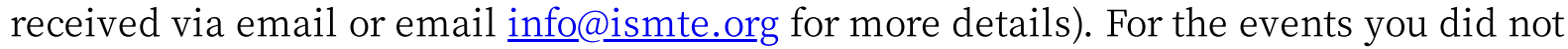
attend, each individual session is available for $\$ 25$. We encourage you and your 
colleagues at your organization to watch these sessions as you have time, picking up the latest information about pressing issues in the field.

\section{Take Time to Connect and Learn}

With so many of us still working remotely fulltime, it' s more important than ever to find ways to connect with one another. ISMTE can help you with that. In just the last few months, we' ve offered myriad ways to learn new things while linking up with your peers in the field. Through our webinars, local group and early-career meet-ups, and our newest program-ISMTE Office Hours-we' ve helped keep you abreast of changes in the industry while providing you with the chance to see familiar faces. With ISMTE Office Hours, we offer virtual, one-hour informal meet-ups where a single topic is discussed by the attendees. Office Hours are facilitated by an ISMTE member who has an interest in the topic at hand-if you are interested in hosting an Office Hours session, please submit your topic idea using this form.

\section{ISMTE is Turning 15!}

Wow-time flies! Next year ISMTE will celebrate its 15th year. We' ve been busily preparing for this milestone by brainstorming ideas for activities and events for 2022. We' re investigating a special EON series, a time capsule, a photo archive, interviews and videos with members, raffles, and more. If you' re interested in submitting an idea for how we can pay tribute to ISMTE' s ongoing success, or if you have a photo you' d like to share to get the photo archive started, please email us at info@ismte.org.

As always, if you have any feedback for the ISMTE BOD or would like to volunteer for any of our committees, please contact us at: $\underline{\text { info@ismte.org. }}$

\section{Call for Volunteers}




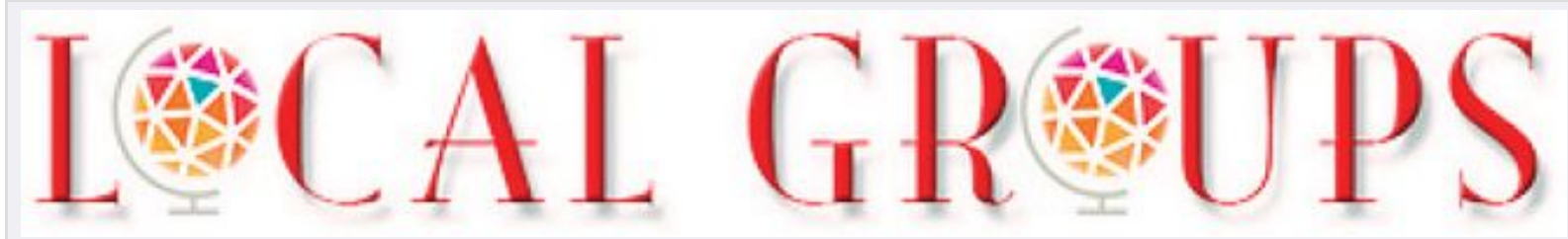

ISMTE Local Groups have formed through the efforts of members who would like to meet with peers and colleagues in their local area for networking and discussion. Participation is not limited to ISMTE members, and there is no cost to join a group.

Active Groups:

- Australia

- Boston, MA

- Chicagoland, IL

- Dallas, TX

- Denver, CO

- Heidelberg, Germany

- Kathmandu, Nepal

- London, UK

- New York, NY

- North Carolina - Research Triangle Park

- Oxford, UK

- Pacific Coast, USA

- Rochester, NY

- Russia

- Tokyo, Japan

- Washington, DC

Visit the ISMTE Local Groups page to join a local group or to find more information. 